\title{
WIJZE VAN CONCEPTIE EN TIJD TOT ZWANGERSCHAP ALS INDICATOREN VAN VRUCHTBAARHEID IN EEN VLAAMSE GEBOORTECOHORT
}

Cécile Guérin ${ }^{1}$, Eline Vandebroek ${ }^{1}$, Mathieu Roelants ${ }^{1}$, Karla Van Leeuwen ${ }^{2}$, Annemie Desoete ${ }^{3}$, Roeljan Wiersema ${ }^{3}$, Karel Hoppenbrouwers ${ }^{1}$

\footnotetext{
${ }^{1}$ Centrum Omgeving en Gezondheid, Jeugdgezondheidszorg, Universiteit Leuven, Leuven, België

${ }^{2}$ Onderzoeksgroep Gezins- en Orthopedagogiek, Universiteit Leuven, Leuven, België

${ }^{3}$ Vakgroep Experimenteel Klinische en Gezondheidspsychologie, Universiteit Gent, Gent, België
}

\section{Corresponderend auteur:}

Mathieu Roelants,

Centrum Omgeving en Gezondheid - Jeugdgezondheidszorg

Universiteit Leuven

Kapucijnenvoer 35, 3000 Leuven, België

E-mail: mathieu.roelants @kuleuven.be

Trefwoorden: tijd tot zwangerschap, geplande en ongeplande zwangerschap, vruchtbaarheidsbehandeling, determinanten van vruchtbaarheid, infertiliteit

\section{Samenvatting}

Naast sociale en economische factoren wordt verminderde vruchtbaarheid genoemd als oorzaak van het dalende geboortecijfer in Vlaanderen. De tijd die nodig is om tot een gewenste, natuurlijke bevruchting te komen, de zogenaamde 'tijd tot zwangerschap' (kortweg TTZ), is een maat voor het schatten van de prevalentie van verminderde vruchtbaarheid in een bevolking ( $T T Z>12$ maanden). Het doel van deze studie is een beschrijving te geven van de wijze van conceptie en duurtijd tot zwangerschap van kinderen in Vlaanderen, en een analyse van determinanten van TTZ. In de Vlaamse geboortecohortstudie JOnG! (2008-2009) werden ouders van 2016 zuigelingen bevraagd over de wijze van conceptie en de tijd tot de zwangerschap van hun kind. Er werden vier groepen onderscheiden, namelijk vruchtbaarheidsbehandeling (10,2\%), niet-geplande natuurlijke zwangerschap $(11,9 \%)$, geplande spontane zwangerschap met TTZ $\leq 12 \mathrm{~m}(70,0 \%)$ en geplande spontane zwangerschap met TTZ >12m (5,6\%). Van 2,3\% was de TTZ niet gekend. Factoren die een TTZ >12m beïnvloeden werden geanalyseerd d.m.v. logistische regressie. Laag opleidingsniveau van ouders $(O R=2,51 ; p=0,008)$ en 
leeftijd van moeder en vader $>35$ jaar (respectievelijk $O R=4,59$ en 3,21 ; beide $p<0,001$ ), blijken significant geassocieerd met TTZ $>12 \mathrm{~m}$. Voor roken van moeder voor de zwangerschap is dit na correctie voor de andere determinanten niet het geval. De prevalentie van ongeplande zwangerschap ligt in de lijn van die in andere Europese landen, en is sociaaleconomisch bepaald. De impact van persoonlijke en/of omgevingsfactoren op de vruchtbaarheid van koppels in Vlaanderen wordt hiermee bevestigd.

\section{Inleiding}

In 2018 werden in Vlaanderen 64336 kinderen geboren bij vrouwen met een (officiële) woonplaats in het Vlaamse Gewest. Dat zijn er 0,3\% minder dan in 2017 en 8,2\% minder dan in 2010.[1] Het totale vruchtbaarheidscijfer (TVC) is in dezelfde periode gedaald van 1,80 geboorten per vrouw in 2010 naar 1,58 in 2018. Het TVC is een goede indicator voor de mate waarin vrouwen in een bepaald kalenderjaar kinderen krijgen. Het wordt berekend als de optelsom van de leeftijdsspecifieke vruchtbaarheidscijfers (LVC) over de vruchtbare levensjaren (per conventie vastgesteld als 15 - 49 jaar). De LVC voor een bepaald jaar is het aantal kinderen dat 100 vrouwen van die leeftijd voortbrengen in dat jaar. De daling van de LVC is in de hoger vermelde periode het grootst in de leeftijdsgroep 20-24 jaar, en wordt slechts gedeeltelijk gecompenseerd door een stijging in oudere leeftijdsgroepen.[2] De trend naar zwangerschap op oudere leeftijd baart zorgen, omdat de kans op infertiliteit toeneemt met de leeftijd van de vrouw. Volgens de 'International glossary on infertility and fertility care (IGIFC)' wordt infertiliteit gedefinieerd als "de aandoening die gekenmerkt is door de onmogelijkheid om een klinisch bevestigde zwangerschap tot stand te brengen na 12 maanden van regelmatig, onbeschermd seksueel contact".[3] Van deze definitie is het begrip 'time to pregnancy' (verder 'tijd tot zwangerschap', TTZ, genoemd) afgeleid, wat staat voor de tijd die een koppel nodig heeft om een tot een geplande natuurlijke zwangerschap te komen. Volgens het hogervermelde criterium van TTZ $>12 \mathrm{~m}$ wordt de prevalentie van infertiliteit in de Westerse wereld geraamd op 1 op 7 koppels.[4] Volgens IGIFC zijn de termen infertiliteit en subfertiliteit onderling inwisselbaar[3]. Op basis van wiskundige modellen blijkt TTZ $>12 \mathrm{~m}$ hiervoor een redelijk betrouwbare indicator te zijn, alhoewel afhankelijk van specifieke kenmerken van het koppel (bv. leeftijd van de vrouw, of een gezondheidsprobleem dat de intrinsieke vruchtbaarheid beïnvloedt, zoals diabetes) een kleiner of groter aantal menstruele cycli als bijkomend criterium aangewezen kan zijn.[5]

Vruchtbaarheidsproblemen zorgen niet alleen voor een psychosociale belasting van de betrokken partners, maar zijn ook geassocieerd met een verhoogd risico op miskraam, extra-uteriene zwangerschap, premature geboorte en laag geboortegewicht.[6,7] Naarmate het langer duurt om 
zwanger te geraken, neemt de kans toe dat een koppel overgaat tot geassisteerde vruchtbaarheidsbehandeling, zoals hormonale ovulatiestimulatie, in vitro fertilisatie (IVF) of intracytoplasmatische sperma injectie (ICSI). Onderzoek heeft bevestigd dat vruchtbaarheidsbehandelingen correleren met een toegenomen risico voor preterme geboorte, laag geboortegewicht, nood aan intensieve zorgen en perinataal overlijden.[8] Daarnaast zou er een groter risico zijn voor ontwikkelingsachterstand bij kinderen geboren na geassisteerde bevruchting, alhoewel de verschillen met kinderen geboren na spontane conceptie klein zijn, en de klinische relevantie ervan niet is bevestigd. $[9,10]$ In welke mate de verminderde vruchtbaarheid op zich, ofwel eerder de vruchtbaarheidsbehandeling, geassocieerd is met nadelige perinatale gezondheidsuitkomsten is niet goed gedocumenteerd.[11,12] Verschillende studies hebben de voorspellende waarde van biologische kenmerken van de moeder (zoals leeftijd, lengte van de menstruele cyclus, haar eigen geboortegewicht en body mass index voor de zwangerschap)[13,14] en vader (leeftijd)[15,16], alsook van ouderlijke leefstijl en sociaaleconomische factoren[16,17,18], op TTZ gedocumenteerd.

In de Vlaamse Geboortecohortstudie JOnG!, is een set van ouderkarakteristieken opgenomen die een interessante aanvulling is op de internationaal beschikbare gegevens over de invloed van sociale en leefstijlfactoren op de vruchtbaarheid. Ook het vergelijken van kenmerken van kinderen geboren na ongeplande zwangerschap, vruchtbaarheidsbehandeling, of natuurlijke, geplande conceptie, in een grootschalige cohortstudie levert potentieel belangrijke informatie voor de volksgezondheid.

Het doel van deze studie is het beschrijven en vergelijken van relevante kenmerken in groepen van kinderen volgens de wijze van conceptie en de duurtijd tot zwangerschap.

\section{Methoden}

\section{Steekproef}

In de Vlaamse geboortecohortstudie JOnG! werd volgens een toevalstrekking in twee fasen een steekproef gevormd. Vooreerst werden in Vlaanderen en Brussel negen regio's geselecteerd (zoals omschreven door Kind en Gezin voor haar consultatiebureaus), rekening houdend met sociaaleconomische kenmerken en herkomst van de bewoners, graad van stedelijkheid en regionale spreiding. Ouders van alle pasgeborenen in de geselecteerde regio's en geboren op een oneven dag tussen 1 mei 2008 en 30 april 2009 ( $N=5161)$ werden uitgenodigd om aan het onderzoek deel te nemen. Voor 3017 kinderen werd door ouders toestemming tot deelname gegeven voor de studie (d.i. $58,4 \%$ van de uitgenodigden). Gemiddeld 6,3 weken na de bevalling (en $90 \%$ vóór 14 weken na de bevalling) zijn de moeders van deze pasgeborenen bevraagd over het tot stand komen van de zwangerschap van hun kind. Van de ouders van 2106 (69,8\% van de deelnemers) kinderen ontvingen 
we de ingevulde vragenlijsten (Figuur 1). Voor een uitgebreide beschrijving van de steekproef en de procedures en inhoud van de bevraging verwijzen we naar het betreffende onderzoeksrapport.[19]

\section{Instrumenten en variabelen}

Aan de deelnemende ouders (bij voorkeur de moeder) werd schriftelijk gevraagd naar de tijd die nodig was om zwanger te worden van hun pasgeboren kind (te rekenen vanaf het moment dat de ouders hier pogingen toe ondernamen). Bij deze vraag moest één van de volgende antwoordmogelijkheden aangekruist worden: 'ik weet het niet', 'de zwangerschap was niet gepland', '0-3 maanden', '4-6 maanden', '7-9 maanden', '10-12 maanden', '13-18 maanden', '19-24 maanden', 'meer dan 24 maanden'. Bijkomend werd gevraagd of de conceptie op natuurlijke wijze of via medische interventie tot stand kwam. In het tweede geval werd een reeks van antwoordmogelijkheden voorzien, waaronder hormonale ovulatiestimulatie, in vitrofertilisatie (IVF) en intracytoplasmatische sperma-injectie (ICSI), alsook een open veld voor eventuele andere methoden. Indien meer dan één antwoordmogelijkheid werd aangekruist, werd de meest invasieve interventie weerhouden voor de analyse.

Op basis van deze informatie werd de steekproef ingedeeld in vier groepen (Figuur 1): (A) kinderen geboren na vruchtbaarheidsbehandeling, (B) kinderen geboren na een ongeplande zwangerschap, (C) kinderen geboren na een geplande natuurlijke zwangerschap met een TTZ $\leq 12 \mathrm{~m}$, en (D) kinderen geboren na een geplande natuurlijke zwangerschap met een $T T Z>12 m$. De kinderen die na een geplande natuurlijke zwangerschap geboren zijn, maar voor wie de TTZ niet gekend was, werden niet in de analyse opgenomen $(n=49)$.

Voor de determinantenanalyse werden zowel sociaaleconomische kenmerken van ouders en/of kind (nationaliteit en leeftijd van moeder en vader bij de geboorte van hun kind, hoogst behaalde diploma van moeder en/of vader, maandelijks gezinsinkomen, gezinssamenstelling, geslacht van het kind en rangorde van het kind in het gezin (pariteit)), als gezondheidsgerelateerd gedrag van de moeder (alcoholgebruik en roken) vóór de zwangerschap in rekening gebracht. Om de geboorteparameters tussen groepen te kunnen vergelijken, werden bijkomend de duur van de zwangerschap en het geboortegewicht van het kind in de analyses opgenomen. Tabel 1 biedt een overzicht van deze variabelen, alsook de antwoordcategorieën die in de analyses werden gebruikt.

\section{Statistische analyses}

In een eerste stap werd de verdeling van kenmerken in de vier groepen beschreven en vergeleken door middel van chi-kwadraattesten. Vervolgens werd voor de geplande zwangerschappen nagegaan of er een significant verschil was naargelang de TTZ, door groep C (TTZ $\leq 12 \mathrm{~m})$ te vergelijken met groep $D$ (TTZ $>12 m$ ) door middel van enkelvoudige logistische regressieanalyse. De factoren die significant verschilden naargelang de TTZ werden uiteindelijk geïncludeerd in een meervoudige logistische 
regressieanalyse met 'backward selection'. Uit voorgaande studies bleek pariteit (rangorde van het kind in het gezin) bepalend voor de TTZ en daarom werd deze ook in het model opgenomen, alhoewel er geen statistische significantie $(p=0,09)$ werd bekomen in de enkelvoudige regressieanalyse. Bijkomend werden kinderen geboren na vruchtbaarheidsbehandeling (groep A), na ongeplande zwangerschap (groep B) en na geplande natuurlijke zwangerschap (groepen C en D samen) onderling vergeleken via enkelvoudige logistische regressieanalyse. Alle analyses werden uitgevoerd via SPSS Statistics 17.0. Een $p$-waarde $<0,05$ werd gebruikt als criterium voor statistische significantie.

\section{Resultaten}

Volgens de respondenten werd 10,2\% van de kinderen (215 van de 2106 ) verwekt na een of andere vorm van vruchtbaarheidsbehandeling en 89,8\% (1891 van de 2106) op natuurlijke wijze. Van de 1891 kinderen geboren na een natuurlijke zwangerschap waren er 1474 gepland en verwekt binnen een termijn van 12 maanden, 117 gepland maar pas verwekt na een periode van meer dan 12 maanden, en 251 niet gepland; dit is respectievelijk 70,0\%, 5,6\% en 11,9\% van het totale aantal van 2016 kinderen. Van de respondenten gaven 49 (2,3\%) aan dat de termijn binnen welke de conceptie tot stand kwam niet bekend was (Figuur 1). De frequentieverdeling van de geselecteerde kind- en ouderkenmerken over de vier groepen is weergegeven in tabel 1.

Voor verschillende ouderkenmerken werd met enkelvoudige logistische regressie een significante correlatie met laattijdige conceptie $(T Z>12 \mathrm{~m})$ gevonden, namelijk een leeftijd $>35$ jaar voor vader en moeder bij de geboorte van hun kind (OR respectievelijk 3,21 en 4,59 in vergelijking met de leeftijdsgroep 21-35 jaar; $p<0,001$ ), een laag opleidingsniveau van de ouders ( $O R=2,51$ in vergelijking met gemiddeld opleidingsniveau; $p=0,008)$, en roken van de moeder voor de zwangerschap $(O R=1,60$; $p=0,038$ ) (Tabel 2). Bovendien werd een significante lineaire toename gevonden tussen de TTZ (gegroepeerd per 6 maanden) en de leeftijd van vader en moeder bij de geboorte van hun kind, maar dit verklaarde slechts een fractie van de variatie (respectievelijk $R^{2}=0,035$ en 0,$019 ; p<0,001$ ) (gegevens niet getoond).

De vier hoger vermelde significante factoren werden samen met de pariteit opgenomen in een meervoudige logistische regressieanalyse. Na correctie voor de andere determinanten was roken van de moeder voor de zwangerschap niet langer significant gecorreleerd met TTZ $>12 \mathrm{~m}$, terwijl het verband met de leeftijd van beide ouders, opleidingsniveau van de moeder en pariteit wel werd bevestigd (Tabel 2). Roken door de moeder was niet meer statistisch significant omdat het sterk geassocieerd is met een laag opleidingsniveau (Chi-kwadraat: 64,15; $p<0,001$ ). 
In de groep kinderen geboren na vruchtbaarheidsbehandeling (groep A) is de proportie jongens opmerkelijk lager dan bij kinderen geboren na een natuurlijke zwangerschap (groepen B, C en D samen) (43,7\% versus 51,2\%; $p=0,04)$. Bij koppels met verminderde vruchtbaarheid zijn er significant meer primipara (groepen A en D, respectievelijk 73,0\% en 57,3\%) dan bij vruchtbare koppels (groepen B en C, respectievelijk 40,6\% en 49,1\%)( $p<0,001)$.

$\mathrm{Bij}$ de ongeplande zwangerschappen (groep B) is de proportie laagopgeleide ouders $(20,2 \%)$, gezinnen met een laag inkomen $(17,1 \%)$ of met één of beide ouders van niet-Belgische nationaliteit $(26,7 \%)$ significant groter dan in de andere groepen (alle vergelijkingen, $p<0,001$ ).

Tot slot zijn er in de groep met ongeplande zwangerschap (groep B) en de groep met vruchtbaarheidsbehandeling (groep A) meer alleenstaande moeders (respectievelijk 9,2\% en 5,6\% versus $1,2 \%$ in de groepen met geplande natuurlijke zwangerschap; beide vergelijkingen, $p<0,001)$. Tenslotte zijn kinderen in de groep met vruchtbaarheidsbehandeling (groep A) vaker prematuur $(12,1 \%)$ of dysmatuur (geboortegewicht $<2500 \mathrm{~g}$ bij zwangerschapsduur $\geq 37 \mathrm{w}, 14,0 \%$ ) bij de geboorte in vergelijking met kinderen geboren uit natuurlijke zwangerschappen (respectievelijk 4,6\% en 4,0\% in de drie groepen samen; $p<0,001)$.

\section{Discussie}

Uit dit onderzoek blijkt dat in Vlaanderen 10,2\% van de kinderen verwekt werden na een vruchtbaarheidsbehandeling, en dat 7,4\% van de natuurlijk zwangerschappen pas na meer dan 12 maanden tot stand kwamen. De tijd nodig om zwanger te geraken is een eenvoudige en gebruikelijke maat voor onderzoek van vruchtbaarheid. Deze cijfers zijn gebaseerd op een ruime steekproef van Vlaamse pasgeborenen met een relatief hoge respons (bijna 60\% van de uitgenodigden werd geïncludeerd, en voor $70 \%$ van hen werd een vragenlijst ingevuld), en voor een aantal belangrijke demografische en sociaaleconomische kenmerken representatief voor dit geboortecohort.[20]

De indeling in vier groepen levert kencijfers over de wijze van conceptie en de tijdsduur tot zwangerschap in Vlaanderen. Negen op tien kinderen zijn geboren na een zwangerschap die op een natuurlijke wijze tot stand kwam, waarvan 13,6\% (11,9\% van de totale steekproef) echter niet was gepland. Van de geplande spontane zwangerschappen kwam 7,4\% (5,6\% van de totale steekproef) pas na een periode van meer dan 12 maanden tot stand, wat volgens de internationale definitie overeenstemt met subfertiliteit. Samen met de 10,2\% kinderen die verwekt werden na een vruchtbaarheidsbehandeling kenden dus 15,8\% van de koppels met een pasgeboren kind een of andere vorm van subfertiliteit.

De analyse van factoren bij kinderen geboren na een geplande natuurlijke zwangerschap bevestigt dat een leeftijd $>35 \mathrm{j}$, een laag opleidingsniveau van de ouders, en een eerste zwangerschap, in de periode 
2008-2009 significant geassocieerd zijn met een langere duur $(>12 \mathrm{~m})$ tot geplande conceptie. De associatie van TTZ met de leeftijd van de moeder en met pariteit werd reeds eerder in wetenschappelijke literatuur beschreven.[13,15-17] De invloed van de leeftijd van de vader werd in enkele studies bevestigd.[15,16] Het is echter niet duidelijk of dit enkel verband houdt met gedragsfactoren (zoals bv. verminderde frequentie van coïtus met hogere leeftijd) of veeleer verbonden is aan een met leeftijd gerelateerde daling van de spermakwaliteit. Ook de invloed van het opleidingsniveau van de ouders werd eerder beschreven, en zou kunnen verklaard worden door leefstij|factoren (ongunstig voedingspatroon en leefgewoonten).[16,17] Desondanks konden in onze studie geen vermijdbare leefstijlfactoren geïdentificeerd worden, alhoewel roken van de moeder voor de zwangerschap significant gecorreleerd was met een $T T Z>12 \mathrm{~m}$. Dit effect verdween echter na correctie voor andere relevante factoren, omdat roken door de moeder sterk geassocieerd is met een laag opleidingsniveau. Dat er in onze studie geen invloed van vermijdbare factoren op TTZ kon aangetoond worden, kan verband houden met het feit dat slechts beperkt gepeild werd naar leefstijl van ouders. Belangrijke factoren die potentieel de TTZ kunnen beïnvloeden, zoals contraceptiegebruik voor de periode van poging tot zwangerschap, lengte van de menstruele cyclus, body mass index en geboortegewicht van de moeder, werden niet bevraagd.

Een beperking van deze studie is eveneens het feit dat de gegevens afkomstig zijn van een steekproef in een geboortecohort, en dus per definitie onvruchtbare koppels of koppels met een gewilde of ongewilde zwangerschapsonderbreking niet in de cijfers vertegenwoordigd zijn. Ook werd de TTZ op een retrospectieve manier gedocumenteerd door bevraging van ouders. Dit gebeurde echter kort (gemiddeld 6 weken) na de bevalling, waardoor een eventuele 'herinneringsbias' en misclassificatie in functie van TTZ tot een minimum werd beperkt.[21]

Om een zo volledig mogelijk beeld te hebben van de wijze van conceptie en de tijd nodig tot zwangerschap werden niet alleen de geplande natuurlijke zwangerschappen in rekening gebracht, maar bijkomend aparte analyses verricht voor de groep kinderen geboren na een niet-geplande zwangerschap of na vruchtbaarheidsbehandeling. Hierbij valt op dat in de groep met vruchtbaarheidsbehandeling een significant grotere proportie meisjes geboren werd dan in de drie andere groepen samen. Deze bevinding kon niet bevestigd worden in de literatuur, en is bovendien moeilijk te interpreteren omdat in deze groep verschillende behandelingsmethoden worden samen genomen. Het (niet significante) hogere percentage jongens in de groep met laattijdige conceptie (TTZ $>12 \mathrm{~m}$ ) stemt echter wel overeen met de bevinding in andere studies dat de kans op een mannelijk nageslacht toeneemt naarmate het langer duurt vooraleer conceptie wordt bereikt.[22] Het moet echter vermeld dat niet alle studies dit verband bevestigen.[23]

De proportie natuurlijke zwangerschappen die ongepland tot stand kwamen $(13,6 \%)$ stemt in onze studie overeen met Nederlandse en Deense cijfers (respectievelijk 13,2\% en 11\%), maar ligt lager dan 
het gemiddelde in West-Europese landen (17\% in 2008).[14,16,24] Of dit laatste verband houdt met verschillen in contraceptiegebruik of in prevalentie van miskraam of geplande abortus is niet duidelijk. Wel valt op dat de kinderen die geboren zijn na een ongeplande zwangerschap gemiddeld meer sociaaleconomische deprivatie (lager opleidingsniveau en gezinsinkomen) kennen en in verhouding vaker ouders hebben met niet-Belgische nationaliteit. Of dit te maken heeft met minder correct gebruik van contraceptie kan op basis van onze cijfers niet bevestigd worden, omdat over het gebruik van contraceptieve methoden geen gegevens verzameld werden, en enkel volledige (niet afgebroken) zwangerschappen in de steekproef werden opgenomen. De grotere proportie van alleenstaande moeders in de groep van niet geplande zwangerschappen is niet onverwacht. In de groep kinderen geboren na vruchtbaarheidsbehandeling is dit mogelijk het resultaat van een bewuste keuze, eerder dan een zuiver probleem van vruchtbaarheid. Zo werden vermoedelijk lesbische vrouwen en bewust ongehuwde vrouwen met kinderwens beschouwd als alleenstaande moeder. Tot slot stemmen ook de hogere prevalenties van prematuriteit en laag geboortegewicht in de groep met vruchtbaarheidsbehandeling overeen met bevindingen in eerder onderzoek.[8]

Samengevat schetst dit onderzoek een beeld van de proportie kinderen die geboren worden na een vruchtbaarheidsbehandeling, alsook van de duurtijd tot conceptie voor kinderen geboren na een natuurlijke zwangerschap. Volgens internationaal erkende criteria werd 5,6\% van de kinderen geboren na een zwangerschap die pas na meer dan 12 maanden tot stand kwam, en nog eens 10,2\% van de kinderen na een zwangerschap die tot stand kwam met vruchtbaarheidsbehandeling. De studie biedt verder inzicht in sociaaleconomische factoren die verband houden met verminderde vruchtbaarheid, maar het effect van de (in deze studie gedocumenteerde) vermijdbare factoren is beperkt.

\section{Referenties}

1. Statistiek Vlaanderen. www.statistiekvlaanderen.be/nl/geboorten-0. Geraadpleegd op: 14 mei 2020.

2. Kind en Gezin. www.kindengezin.be/cijfers-en-rapporten/cijfers/vruchtbaarheidscijfers. Geraadpleegd op: 14 mei 2020.

3. Zegers-Hochschild F, Adamson G, Dyer S et al. The International Glossary of Infertility and Fertility Care 2017. Fertil Steril 2017;108(3):393-406.

4. Mascarenhas M, Flaxman S, Boerma T, Vanderpoel S, Stevens C. National, regional and global trends in infertility prevalence since 1990: a systematic analysis of 277 health surveys. PLoS Med 2012;9(12):e1001356. 
5. Sozou P, Martshorne G. Time to pregnancy: a computational method for using duration of nonconception for predicting conception. PLoS ONE 2012;7(10):e46544.

6. Axmon A, Hagmar L. Time to pregnancy and pregnancy outcome. Fertil Steril 2005;84(4):966-974.

7. Messerlian C, Maclagan L, Basso O. Infertility and the risk of adverse pregnancy outcomes: a systematic review and meta-analysis. Hum Reprod 2013;28(1):125-137.

8. Helmerhorst F, Perquin D, Donker D, Keirse M. Perinatal outcome of singletons and twins after assisted conception: a systematic review of controlled studies. BMJ 2004;328(7434):261-264.

9. Hvidtjørn D, Schieve L, Schendel D, Jacobsson B, Svaerke C, Thorsen P. Cerebral palsy, autism spectrum disorders, and developmental delay in children born after assisted conception: a systematic review and meta-analysis. Arch Pediatr Adolesc Med 2009;163(1):72-83.

10. Zhu J, Basso O, Obel C, Hvidtjørn D, Olsen J. Infertility, infertility treatment and psychomotor development: the Danish National Birth Cohort. Paediatr Perinat Epidemiol 2009;23(2):98-106.

11. Romundstad L, Romundstad P, Sunde A, et al. Effects of technology or maternal factors on perinatal outcome after assisted fertilisation: a population-based cohort study. Lancet 2008;372(9640):737-743.

12. Belva F. Health of ICSI children. Doctoral thesis in Medical Sciences, Bonduelle, M (promoter), De Schepper J \& Tournaye H (co-promoters). Free University Brussels, 2012.

13. Axmon A, Rylander L, Albin M, Hagmar L. Factors affecting time to pregnancy. Hum Reprod 2006;21(5):1279-1284.

14. Nohr E, Vaeth $\mathrm{M}$, Rasmussen $\mathrm{S}$, Ramlau-Hansen $\mathrm{CH}$, Olsen J. Waiting time to pregnancy according to maternal birthweight and prepregnancy BMI. Hum Reprod 2009;24(1):226-232.

15. Ford W, North K, Taylor H, Farrow A, Hull MG, Golding J. Increasing paternal age is associated with delayed conception in a large population of fertile couples: evidence for declining fecundity in older men. The ALSPAC Study Team (Avon Longitudinal Study of Pregnancy and Childhood). Hum Reprod 2000;15(8):1703-1708.

16. Mutsaerts $M$, Groen $H$, Huiting $H$, et al. The influence of maternal and paternal factors on time to pregnancy - a Dutch population-based birth-cohort study: the GECKO Drenthe study. Hum Reprod 2012;27(2):583-593.

17. McLain A, Sundaram R, Cooney M, Gollenberg A, Buck Louis G. Clustering of fecundability within women. Paediatr Perinat Epidemiol 2011;25(5):460-465.

18. Hassan M, Killick S. Negative lifestyle is associated with a significant reduction in fecundity. Fertil Steril 2004;81(2):384-392.

19. Grietens H, Hoppenbrouwers K, Desoete A, Wiersema J-R, Van Leeuwen K. JOnG! Theoretische achtergronden, onderzoeksopzet en verloop van het eerste meetmoment. Steunpunt Welzijn 
Volksgezondheid en Gezin. Rapport. Leuven. 2010. https://steunpuntwvg.be/images/swvg-1publicaties/2010 02-r11-jong-eerste-meetmoment.

20. Guérin C, Roelants M, Van Leeuwen K, Desoete A, Hoppenbrouwers K. Sociaal-demografisch profiel, perinatale gezondheid en gezondheid tijdens de eerste levensweken van de Vlaamsegeboortecohorte JOnG!. Steunpunt Welzijn Volksgezondheid en Gezin. Rapport. Leuven. 2011. https://steunpuntwvg.be/ (zoek op 'Publicaties' - '2007-2011' - 'Longitudinale studie JOnG' - 'Rapporten').

21. Joffe M, Key J, Best N, Keiding N, Scheike T, Jensen TK. Studying time to pregnancy by use of a retrospective design. Am J Epidemiol 2005;162(2):115-124.

22. Smits L, de Bie R, Essed G, van den Brandt P. Time to pregnancy and sex of offspring: cohort study. BMJ 2005;331(7530):1437-1438.

23. Joffe M, Bennett J, Best N, Jensen TK. Sex ratio and time to pregnancy: analysis of four large European population surveys. BMJ 2007;334(7592):524.

24. Singh S, Sedgh G, Hussain R. Unintended pregnancy: worldwide levels, trends and outcomes. Stud Fam Plann 2010;41(4):241-250. 


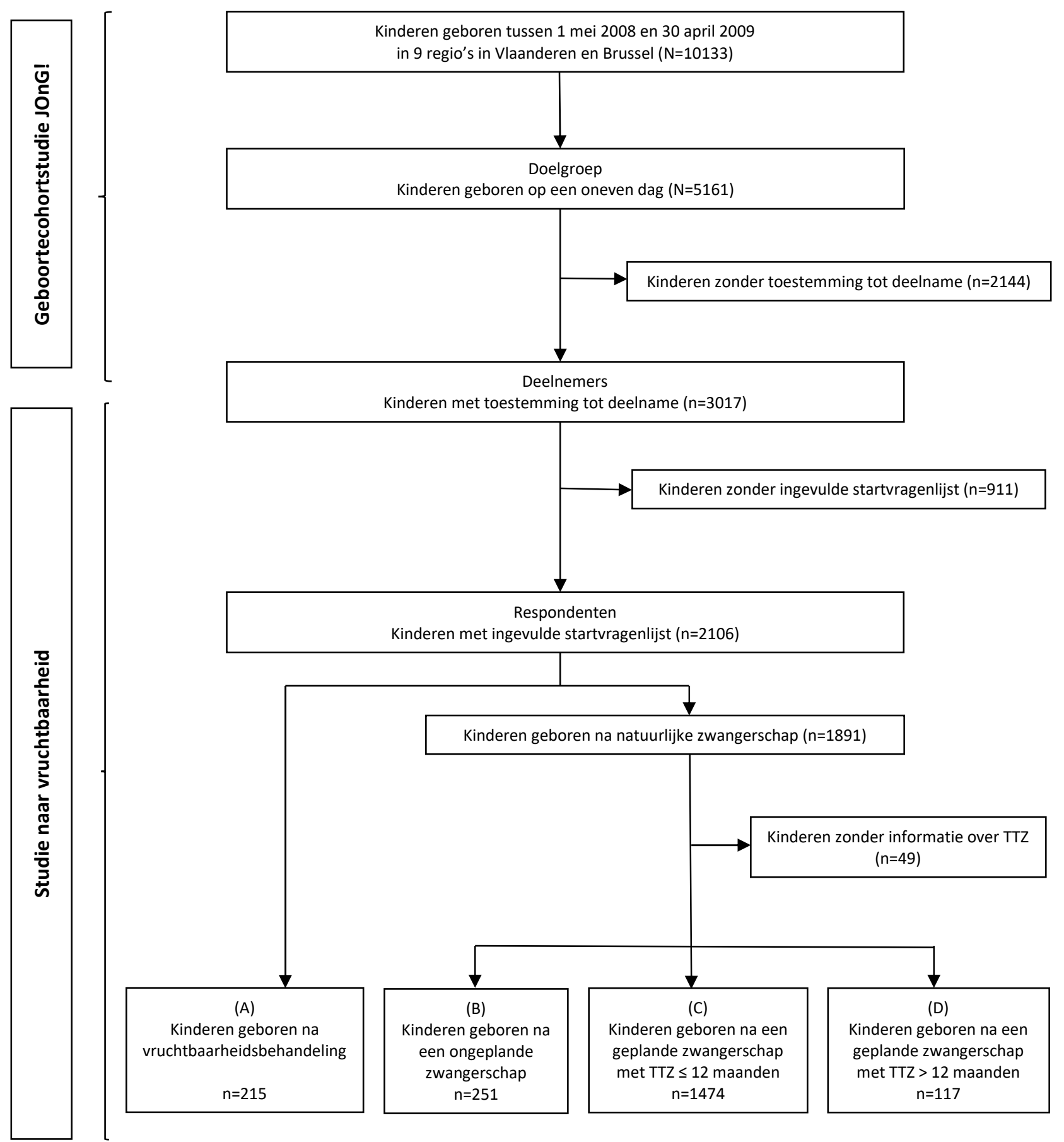

Figuur 1: Schematisch overzicht van steekproeftrekking in de Vlaamse Geboortecohortstudie JOnG! en samenstelling van subgroepen voor de studie naar vruchtbaarheid (TTZ=tijd tot zwangerschap) 
Tabel 1: Kenmerken ${ }^{¥}$ van de vier subgroepen van de studie naar vruchtbaarheid

\begin{tabular}{|c|c|c|c|c|}
\hline & $\begin{array}{c}\text { (A) } \\
\text { Kinderen geboren na } \\
\text { vruchtbaarheids- } \\
\text { behandeling } \\
\text { n (\%) }\end{array}$ & $\begin{array}{c}\text { (B) } \\
\text { Kinderen geboren na } \\
\text { een ongeplande } \\
\text { zwangerschap } \\
\text { n (\%) }\end{array}$ & $\begin{array}{c}\text { (C) } \\
\text { Kinderen geboren na } \\
\text { een geplande } \\
\text { zwangerschap met } \\
\text { TTZ } \leq 12 \text { maanden* } \\
\text { n (\%) }\end{array}$ & $\begin{array}{c}\text { (D) } \\
\text { Kinderen geboren na } \\
\text { een geplande } \\
\text { zwangerschap met } \\
\text { TTZ > } 12 \text { maanden* } \\
\text { n (\%) }\end{array}$ \\
\hline Totaal** & $215(100,0)$ & $251(100,0)$ & $1474(100,0)$ & $117(100,0)$ \\
\hline \multicolumn{5}{|l|}{ Geslacht van het kind } \\
\hline Man & $94(43,7)$ & $119(47,4)$ & $760(51,6)$ & $66(56,4)$ \\
\hline Vrouw & $121(56,3)$ & $132(52,6)$ & $714(48,4)$ & $51(43,6)$ \\
\hline \multicolumn{5}{|l|}{ Leeftijd moeder (jaren) ${ }^{1}$} \\
\hline$<21$ & $1(0,5)$ & $20(8,0)$ & $6(0,4)$ & $1(0,9)$ \\
\hline $21-35$ & $180(83,7)$ & $200(80,0)$ & $1376(93,4)$ & $89(76,1)$ \\
\hline$>35$ & $34(15,8)$ & $30(12,0)$ & $91(6,2)$ & $27(23,1)$ \\
\hline \multicolumn{5}{|l|}{$\begin{array}{l}\text { Hoogste opleidingsniveau } \\
\text { van een van de ouders }{ }^{2}\end{array}$} \\
\hline Laag & $9(4,2)$ & $50(20,2)$ & $65(4,4)$ & $14(12,2)$ \\
\hline Midden & $56(26,0)$ & $97(39,1)$ & $361(24,6)$ & $31(27,0)$ \\
\hline Hoog & $150(69,8)$ & $101(40,7)$ & $1039(70,9)$ & $70(60,9)$ \\
\hline \multicolumn{5}{|l|}{ Nationaliteit } \\
\hline Beide ouders Belg & $183(85,1)$ & $184(73,3)$ & $1296(87,9)$ & $104(88,9)$ \\
\hline $\begin{array}{l}\text { Minstens één ouder } \\
\text { niet-Belg }\end{array}$ & $32(14,9)$ & $67(26,7)$ & $178(12,1)$ & $13(11,1)$ \\
\hline \multicolumn{5}{|c|}{ Maandelijks gezinsinkomen ${ }^{3}$} \\
\hline Laag & $12(5,6)$ & $43(17,1)$ & $78(5,3)$ & $6(5,1)$ \\
\hline Midden & $91(42,3)$ & $115(45,8)$ & $569(38,6)$ & $48(41,0)$ \\
\hline Hoog & $71(33,0)$ & $47(18,7)$ & $560(38,0)$ & $38(32,5)$ \\
\hline Onbekend & $41(19,1)$ & $46(18,3)$ & $267(18,1)$ & $25(21,4)$ \\
\hline \multicolumn{5}{|l|}{ Geboortegewicht (gram) } \\
\hline$<2500$ & $30(14,0)$ & $4(1,6)$ & $63(4,3)$ & $(6,0)$ \\
\hline$\geq 2500$ & $185(86,0)$ & $246(98,4)$ & $1411(95,7)$ & $110(94,0)$ \\
\hline \multicolumn{5}{|l|}{ Preterme geboorte $(<37 w)$} \\
\hline $\mathrm{Ja}$ & $26(12,1)$ & $8(3,2)$ & $71(4,8)$ & $5(4,3)$ \\
\hline Neen & $189(87,9)$ & $243(96,8)$ & $1403(95,2)$ & $112(95,7)$ \\
\hline \multicolumn{5}{|l|}{ Pariteit ${ }^{4}$} \\
\hline 0 & $157(73,0)$ & $102(40,6)$ & $724(49,1)$ & $67(57,3)$ \\
\hline $1+$ & $58(27,0)$ & $149(59,4)$ & $750(50,9)$ & $50(42,7)$ \\
\hline \multicolumn{5}{|l|}{ Alleenstaande moeder } \\
\hline $\mathrm{Ja}$ & $12(5,6)$ & $23(9,3)$ & $17(1,2)$ & $2(1,7)$ \\
\hline Neen & $201(94,4)$ & $223(90,7)$ & $1446(98,8)$ & $114(98,3)$ \\
\hline \multicolumn{5}{|l|}{ Leeftijd vader (jaren) ${ }^{1}$} \\
\hline$<21$ & $3(1,5)$ & $7(3,2)$ & $5(0,4)$ & $0(0,0)$ \\
\hline $21-35$ & $128(66,0)$ & $151(68,0)$ & $1121(79,6)$ & $63(55,3)$ \\
\hline$>35$ & $63(32,5)$ & $64(28,8)$ & $283(20,1)$ & $51(44,7)$ \\
\hline \multicolumn{5}{|c|}{$\begin{array}{l}\text { Alcoholgebruik moeder voor } \\
\text { zwangerschap }\end{array}$} \\
\hline $\mathrm{Ja}$ & $140(65,1)$ & $135(55,8)$ & $1000(68,4)$ & $83(70,9)$ \\
\hline Neen & $75(34,9)$ & $109(44,7)$ & $462(31,6)$ & $34(29,1)$ \\
\hline \multicolumn{5}{|l|}{$\begin{array}{l}\text { Tabakgebruik moeder voor } \\
\text { zwangerschap }\end{array}$} \\
\hline $\mathrm{Ja}$ & $36(16,7)$ & $85(34,6)$ & $308(21,1)$ & $32(27,8)$ \\
\hline Neen & $179(83,3)$ & $161(65,4)$ & $1154(78,9)$ & $83(72,2)$ \\
\hline
\end{tabular}

${ }^{\sharp}$ De verdeling van alle kenmerken is significant verschillend $\left(C^{2} i^{2}\right.$-test) naargelang de groep $(p<0,001)$, behalve het geslacht $(p=0,07)$

*TTZ = tijd tot zwangerschap

**Voor elk kenmerk worden de ontbrekende gegevens (aantal varieert van 1 tot 118) niet getoond en niet in de percentages opgenomen

${ }^{1}$ Leeftijd op het moment van de geboorte van het kind

${ }^{2}$ Opleidingsniveau: laag = minder dan diploma secundaire school, midden = diploma secundaire school, hoog = diploma hoger dan

secundaire school

${ }^{3}$ Maandelijks gezinsinkomen: laag $=\leq 1500$ euro, midden $=1500-3000$ euro, hoog $=>3000$ euro

${ }^{4}$ Pariteit $=$ rangorde in het gezin: $0=$ enig kind, $1+=$ nog één of meerdere andere kinderen in het gezin 
Tabel 2: Factoren die samenhangen met verminderde vruchtbaarheid (uitgedrukt in tijd tot zwangerschap > 12 maanden). Prevalentie, percentages, odds ratio's (enkelvoudige logistische regressieanalyse) en aangepaste odds ratio's (meervoudige logistische regressieanalyses met 'backward selection') van deze factoren voor de kinderen geboren na een geplande spontane zwangerschap $(n=1591)$ met $T T Z>12$ maanden $(n=117)$, in vergelijking met kinderen geboren na een spontane geplande zwangerschap met TTZ $\leq 12$ maanden $(n=1474)$.

\begin{tabular}{|c|c|c|c|c|}
\hline & \multicolumn{4}{|c|}{ Kinderen geboren na een geplande zwangerschap $(n=1591)$} \\
\hline & $\begin{array}{c}\text { Aantal } \\
\text { TTZ > } 12 \text { maanden } \\
\end{array}$ & $\begin{array}{c}\% ¥ \\
\text { TTZ > } 12 \text { maanden } \\
\end{array}$ & $\begin{array}{c}\text { Odds Ratio } \\
(\mathrm{OR})^{\mathrm{a}}\end{array}$ & $\begin{array}{c}\text { Gecorrigeerde Odds } \\
\text { Ratio }(\mathrm{AOR})^{\mathrm{b}}\end{array}$ \\
\hline $\begin{array}{l}\text { Hoogste opleidingsnivea } \\
\text { de ouders }{ }^{1}\end{array}$ & & $* * *$ & & \\
\hline Laag $(n=79)$ & 14 & 17,7 & $2,51 * *$ & $2,90 * *$ \\
\hline Midden $(n=392)$ & 31 & 7,9 & REF & \\
\hline Hoog $(n=1109)$ & 70 & 6,3 & 0,79 & \\
\hline Leeftijd moeder (jaren) ${ }^{2}$ & & $* * *$ & & \\
\hline$<21(n=7)$ & 1 & 14,3 & 2,58 & \\
\hline $21-35(n=1465)$ & 89 & 6,1 & REF & \\
\hline$>35(n=118)$ & 27 & 22,9 & $4,59 * * *$ & $3,75 * * *$ \\
\hline Leeftijd vader (jaren)² & & $* * *$ & & \\
\hline$<21(n=5)$ & 0 & 0,0 & 0,00 & \\
\hline $21-35(n=1184)$ & 63 & 5,3 & REF & \\
\hline$>35(n=334)$ & 51 & 15,3 & $3,21 * * *$ & $2,65 * * *$ \\
\hline $\begin{array}{l}\text { Tabakgebruik moeder vo } \\
\text { zwangerschap }\end{array}$ & & $*$ & & \\
\hline $\mathrm{Ja}(\mathrm{n}=340)$ & 29 & 10,2 & $1,60 *$ & NS \\
\hline Neen $(n=1237)$ & 86 & 6,7 & REF & \\
\hline Pariteit $^{3}$ & & $\circ$ & & \\
\hline $0(n=791)$ & 67 & 8,5 & REF & \\
\hline $1+(n=800)$ & 50 & 6,3 & $0,72^{\circ}$ & $0,50 * *$ \\
\hline
\end{tabular}

$¥$ De ontbrekende gegevens (aantal variërend van 1 tot 3 ) werden niet in rekening gebracht bij de berekening van de percentages a Enkelvoudige logistische regressieanalyse (odds voor een TTZ > 12 maanden t.o.v. een TTZ $\leq 12$ maanden)

${ }^{\mathrm{b}}$ Meervoudige logistische regressieanalyse (TTZ $>12 \mathrm{~m} / T \mathrm{TZ} \leq 12 \mathrm{~m}$ ), de OR is gecorrigeerd voor andere factoren in het model

${ }^{1}$ Opleidingsniveau: laag = minder dan diploma secundaire school, midden = diploma secundaire school, hoog = diploma hoger dan secundaire school

${ }^{2}$ Leeftijd op het moment van de geboorte van het kind

${ }^{3}$ Pariteit $=$ rangorde in het gezin: $0=$ enig kind, $1+=$ nog één of meerdere andere kinderen in het gezin

Statistisch significante waarden worden in vet weergegeven: ${ }^{*} p<0,05 ;{ }^{* *} p<0,01 ;{ }^{* * *} p<0,001$

${ }^{\circ} \mathrm{p}=0,091$ = niet significant

NS = niet significant $(p>0,1)$ 